ESJ (Elementary School Journal)

Volume 8 No. 3 Desember 2018

\title{
PENGARUH KEMAMPUAN PENGELOLAAN PEMBELAJARAN BERBASIS KONSTRUKTIVISME TERHADAP HASIL BELAJAR PKN KELAS V TAHUN PELAJARAN 2018/2019
}

\author{
Lilia Senja Ilyandani, Ratnawati Susanto* \\ Surel:ratnawati@esaunggul.ac.id
}

\begin{abstract}
:
The purpose of this study was to determine whether there was an effect of the influence of constructivism based of learning management skills on the learning outcomes of students in class $V A$ in the 2018/2019 school year. This research is a quantitative research using survey method. The population in this study were students of class V A totaling 30. Determination of the number of samples was determined using the Slovin formula and obtained a sample of 30 respondents. Data collection techniques in this study use questionnaires. The results of testing the first hypothesis with a partial test $\left(t\right.$ test) obtained thitung $=3.208>_{\text {t table }}$ $=2.048$ with a significance of $0.000<0.05$ means reject Ho and accept H1. Based on these data, it means that the variable constructivism learning has a positive and significant effect on the variables of learning outcomes. Based on these data means the variables of constructivism learning have a positive and significant effect on learning outcomes

Keywords: Constructivism, Learning Outcomes.
\end{abstract}

\begin{abstract}
ABSTRAK :
Tujuan penelitian adalah untuk mengetahui apakah terdapat pengaruh pengaruh kemampuan pengelolaan pembelajaran berbasis konstruktivisme terhadap hasil belajar mata pelajaran pkn di kelas V A tahun pelajaran 2018/2019. Penelitian ini merupakan kuantitatif dengan menggunakan metode survey. Populasi penelitian ini adalah siswa kelas V A yang berjumlah 30. Jumlah sampel ditentukan menggunakan rumus Slovin dan diperoleh sebesar 30 responden. Teknik pengumpulan data pada penelitian ini menggunakan angket. Hasil pengujian pertama di uji parsial (uji t) diperoleh $\mathrm{t}_{\text {hitung }}=$ $3,208>\mathrm{t}_{\text {tabel }}=2,048$ dengan signifikansi $0,000<0,05$ berarti tolak $\mathrm{H}_{\mathrm{o}}$ dan terima $\mathrm{H}_{1}$. Berdasarkan data variabel pembelajaran konstruktivisme berpengaruh secara positif dan signifikan terhadap variabel hasil belajar.
\end{abstract}

Lilia: Pengaruh Kemampuan.... Belajar. 


\section{PENDAHULUAN}

Undang-Undang Sistem Pendidikan Nasional Nomor 20 Tahun 2003, yang didefinisiksan sebagai usaha sadar dan terencana untuk mewujudkan suasana belajar dan proses pembelajaran agar peserta didik secara aktif mengembangkan potensi dirinya dan memiliki kekuatan spiritual, keagamaan, pengendalian diri, kepribadian, kecerdasan, akhlak mulia, serta keterampilan yang diperlukan dirinya. Untuk mewujudkan hal tersebut maka pendidikan harus dilakukan melalui proses pembelajaran guna mengembangkan potensi siswa secara optimal.

Pengembangan potensi siswa, dilakukan guru dalam bentuk bimbingan melalui proses pembelajaran di kelas serta kemampuan merancang pembelajaran, dan kemampuan mengelola kelas. Kemampuan mengelola kelas berarti guru memiliki kemampuan dalam mengkondisikan kelas secara kondusif. Suasana kelas yang kondusif akan memfasilitasi terjadinya interaksi antara guru dan siswa secara edukatif dan efektif.

Berdasarkan studi pendahuluan di SDN Jelambar Baru 01 pagi Jakarta Barat, di peroleh data permasalahan hasil belajar siswa kelas IV A yang menjadi perhatian pihak manajemen sekolah. Hasil belajar siswa kelas IV A pada mata pelajaran PKN lebih rendah dibandingkan dengan standar kriteria ketuntasan belajar $(\geq 75 \%)$ dan memiliki pencapaian terendah pada aspek pengetahuan.

p-ISSN 2407-4934 e-ISSN 2355-1747 ermasalahan a sekolah melakukan pola manajemen berbasis sekolah dengan kebijakan orientasi sekolah terhadap guru kelas tinggi melalui kegiatan orientasi dan pelatihan di tahun 2017/2018 sebagai pembekalan bagi guru dalam menyikapi strategi pembelajaran yang berorientasi pada siswa dengan pola pembelajaran berbasis konstruktivisme. Implementasi dari hasil orientasi pelatihan di tahun pelajaran 2017/2018 ditindaklanjuti dengan kebijakan penerapan pembelajaran berbasis konstruktivisme di kelas tinggi pada tahun 2018/2019.

Menurut (Hanafy, 2014) bahwa belajar adalah perubahan kemampuan yang dimiliki oleh setiap individu dan melalui perubahan dapat memperoleh suatu tingkah laku yang baru secara keseluruhan sebagai hasil dari pengalamannya sendiri dalam berinteraksi dengan lingkungannya. Menurut Gagne dalam Ratna Wilis (2011: 2) belajar merupakan suatu proses dimana setiap individu mengalami perubahan dalam bentuk dari segi perilakunya s ESJ VOLUME 8, NO pengalaman.

Menurut Winkel dalam Purwanto (2010: 45) "perubahan terjadi akibat sikap individu yang berubah dalam hal tingkah lakunya" yang dikutip oleh (Melinda \& Susanto, 2018). Sedangkan menurut (Susanto, 2017) hasil belajar adalah perubahan tingkah laku yang relatif sebagai hasil proses belajar seseorang yang dapat diamati dan diukur dalam bentuk kompetensi, yang terdiri dari pengetahuan, sikap dan keterampilan. Perubahan tersebut dapat 
diartikan sebagai terjadinya peningkatan dan pengembangan yang lebih baik sebelumnya yang tidak tahu menjadi tahu, dari tidak mampu menjadi mampu. Penilaian hasil belajar dapat dinyatakan dalam bentuk kualitatif (mutu kemampuan atau kompetensi) dan secara kuantitatif dalam bentuk skor dan nilai. Bahwa hasil belajar merupakan perubahan tingkah laku yang relatif menetap sebagai hasil proses belajar yang dapat diamati dan diukur mencakup penilaian kemampuan pengetahuan, keterampilan, dan sikap.

Konstruktivisme adalah "mengkostruksi" berarti membangun suatu upaya dalam membentuk tata susunan yang berbudaya modern, dalam konteks filsafat pendidikan. Menurut (Santi,2015) konstruktivisme merupakan pengetahuan pada akhir belajar dan pengetahuan itu sendiri dibangun oleh siswa melalui pengalaman yang telah diperoleh dari hasil intraksi dengan lingkungannya. Teori Vygotsky dalam (Supardan, 2016) konstruktivisme ialah seperangkat aktivitas pengetahuan dalam pembelajaran secara individu untuk mengetahui perkembangan dalam berintraksi dengan individu lainnya dalam memecahkan suatu konteks pembelajaran.

Lebih jauh dijelaskan bahwa di dalam pembelajaran berbasis kontruktivisme, siswa dapat mengembangkan pengetahuannya sendiri sehingga pembelajaran dapat bermakna dan dapat meningkatkan hasil belajar siswa serta dapat melihat siswa aktif dalam proses pembelajaran. Secara garis besar prinsip-prinsip konstruktivisme yang harus diperhatikan adalah: (1) kognitif harus dibangun oleh siswa sendiri baik secara personal maupun secara sosial; (2) kognitif tidak dipindahkan dari guru kepeserta didik, terkecuali dengan keaktifan siswa itu sendiri yang masuk akal; (3) siswa aktif membangun secara terus-menerus, sehingga terjadi perubahan rancangan dalam pembelajaran yang lebih lengkap dan sesuai; (4) guru hanya sekedar membantu menyediakan sarana dan prasarana, agar situasi dalam membangun pengetahuan dapat berjalan dengan baik.

Menurut Ahmad Susanto (2014: 137) ciri-ciri pembelajaran konstruktivisme memiliki ciri-ciri sebagai berikut: (1) pengetahuan dibangun berdasarkan pengalaman atau pengetahuan yang telah ada sebelumnya; (2) belajar merupakan proses yang aktif dimana dalam belajar itu dikembangkan berdasarkan pengalaman; (3) dimana pengetahuan dalam belajar itu dikembangkan dengan adanya perundingan dengan berbagai macam informasi melalui interaksi dengan orang lain; (4) belajar harus dengan kondisi atau situasi yang menyenangkan supaya mendapatkan penilaian yang baik.

\section{METODE PENELITIAN}

Pendekatan penelitian yang Lilia: Pengaruh Kemampuan....

kuantitatif. p-ISSN 2407-4934 dalam pene e-ISSN 2355-1747 survey. Sugiyono (2012:6) dalam 
metode survey, informasi dikumpulkan dari responden dengan menggunakan kuesioner. Yang digunakan untuk menemukan pengaruh kemampuan pengelolaan pem

belajaran berbasis konstruktivisme terhadap hasil belajar.

Penelitian ini menggunakan dua variabel yaitu, variabel independen dan variabel dependen. Kemampuan pengelolaan pembelajaran berbasis konstruktivisme sebagai variabel independen $(\mathrm{X})$ terhadap hasil belajar sebagai variabel dependen (Y). Pengaruh antara independen terhadap dependen digambarkan menurut sebagai berikut:

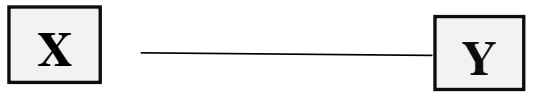

\section{Gambar 1. Model Penelitian}

Keterangan:

$\mathrm{X}$ : Pembelajaran Konstruktivisme

Y: Hasil Belajar

\section{HASIL DAN PEMBAHASAN}

Pada saat penelitian, peneliti memperoleh gambaran pengaruh pengelolaan pembelajaran berbasis konstruktivisme terhadap hasil belajar mata pelajaran PKN di kelas VA di SDN Jelambar Baru 01 Pagi. Instrumen yang digunakan dalam mengumpulkan data adalah angket. Angket yang digunakan merupakan variabel konstruktivisme. Dan hasil belajar yang digunakan diukur dengan menggunakan data hasil penilaian ulangan harian. Memperoleh data sebagai berikut.

a. Variabel Berbasis Konstruktivisme

Pada variabel berbasis konstruktivisme yang digunakan adalah penyebaran angket yang berjumlah 30 butir pernyataan dan jumlah responden sebanyak 30 orang.

Maka dapat diperoleh hasil pada perhitungan data sebagai berikut.

ESJ VOLUME 8, NO. 3, DESEMBER 2018

p-ISSN 2407-4934

e-ISSN 2355-1747
Tabel 1.

Statistika Deskriptif 


\section{Konstruktivisme}

\begin{tabular}{l|l|r}
\hline \multicolumn{2}{c}{ Statistics } \\
\hline $\mathrm{N}$ & Valid & 30 \\
\cline { 2 - 3 } & Missing & 0 \\
\hline Mean & & 102.70 \\
\hline Median & 100.50 \\
\hline Mode & 99 \\
\hline Std. Deviation & 7.391 \\
\hline Variance & 54.631 \\
\hline Range & 29 \\
\hline Minimum & 91 \\
\hline Maximum & 120 \\
\hline
\end{tabular}

Berdasarkan tabel di atas, dapat diketahui hasil perolehan nilai terendah 91 dan nilai tertinggi 120, mean sebesar 102,70, median sebesar 100,50, modus sebesar 99, standar deviasi sebesar
7,391. Adapun tabel distribusi frekuensi konstruktivisme dapat dilihat dalam bentuk.

Tabel 2.

Distribusi Konstruktivisme

\begin{tabular}{c|c|c|c}
\hline Interval & Frekuensi & $\begin{array}{c}\text { Frekuensi Relatif } \\
(\%)\end{array}$ & $\begin{array}{c}\text { Frekuensi Kumulatif } \\
(\%)\end{array}$ \\
\hline $75-77$ & 9 & 30 & 30 \\
\hline $78-80$ & 7 & 23.4 & 53.4 \\
\hline $81-83$ & 6 & 20 & 73.4 \\
\hline $84-87$ & 4 & 13.3 & 86.7 \\
\hline $88-91$ & 3 & 10 & 96.7 \\
\hline $92-95$ & 1 & 3.3 & 100 \\
\hline \multicolumn{2}{c|}{} & & \\
\hline
\end{tabular}

Lilia: Pengaruh Kemampuan....

Tabel distribusi frekuensi di atas dapat dilihat dalam p-ISSN 2407-4934 sebagai berikut. 
Gambar 2.

\section{Grafik Distribusi Frekuensi}

\section{Konstruktivisme}

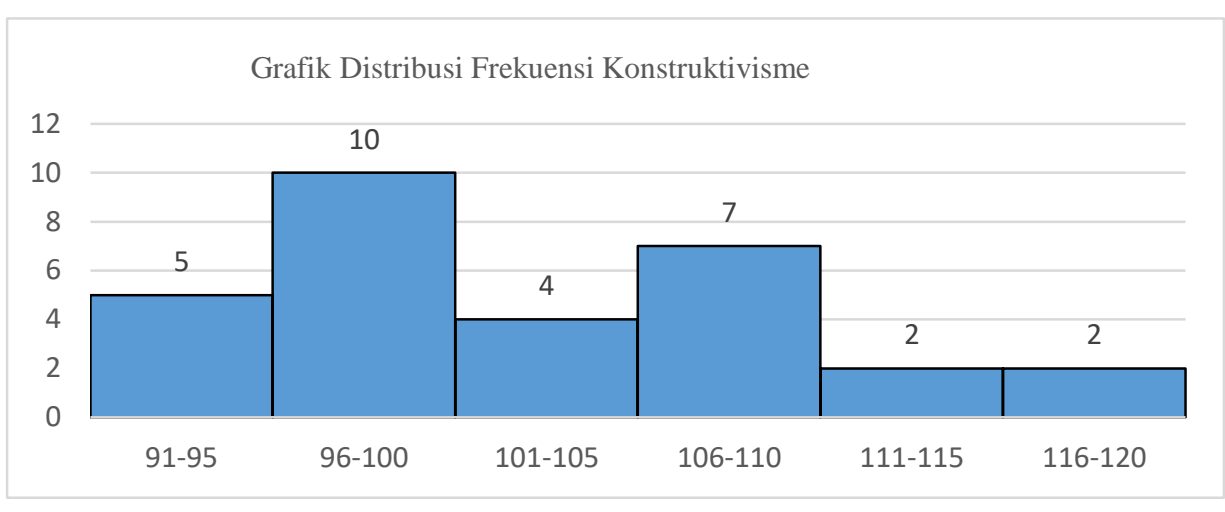

b.

Variabel Hasil Belajar

Pada variabel hasil belajar yang digunakan adalah diukur dengan menggunakan data hasil pe

Tabel 3. Sta ulangan harian mata pelaja PKN yang dilakukan guru. maka dapat diperoleh hasil pada perhitungan data

ESJ VOLUME 8, NO. 3, DESEMBER 2018

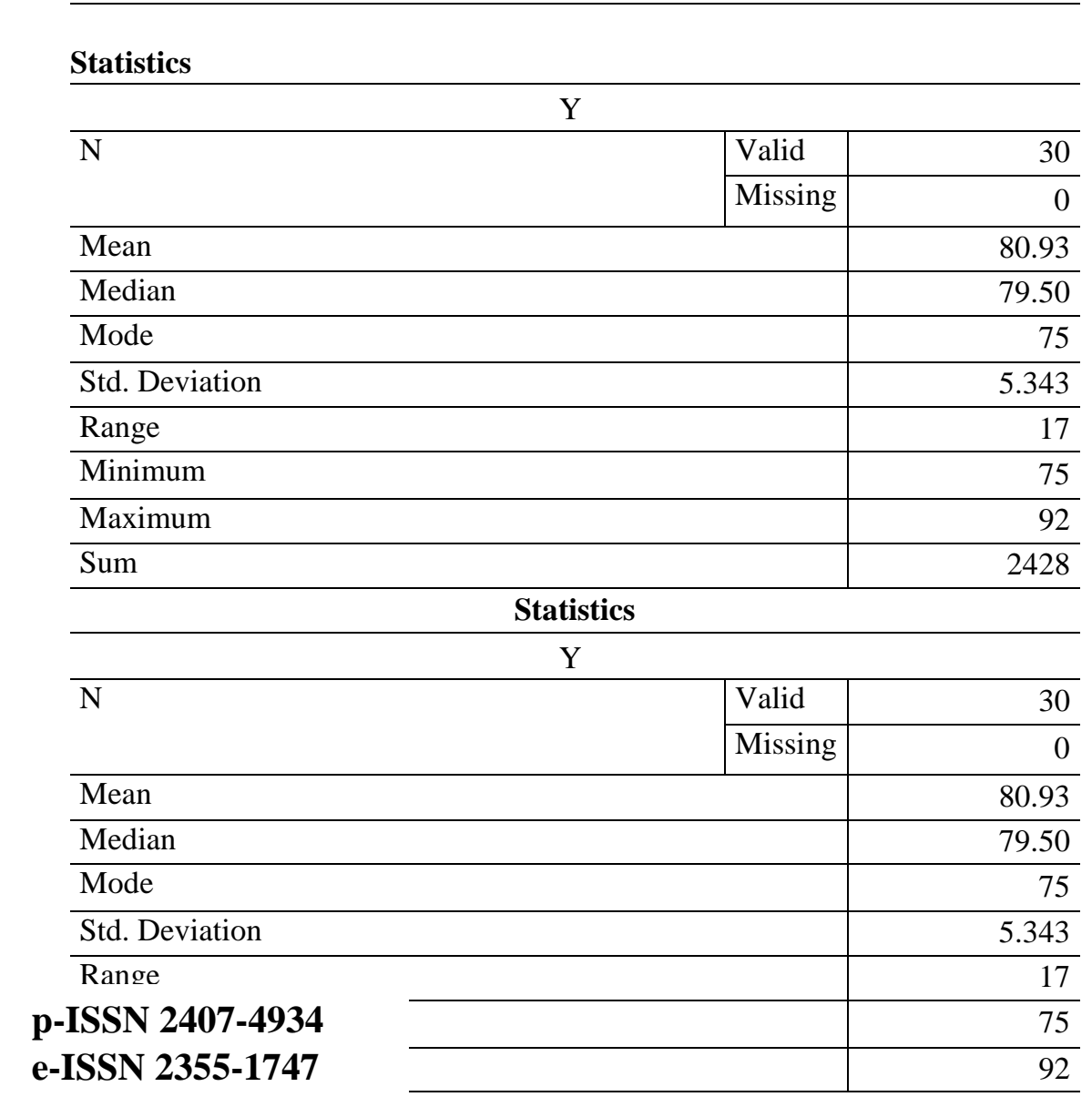




\begin{tabular}{l|r}
\cline { 2 - 3 } Tabel Sum & 2428 \\
\hline
\end{tabular}

4.

\section{Distribusi Hasil Belajar}

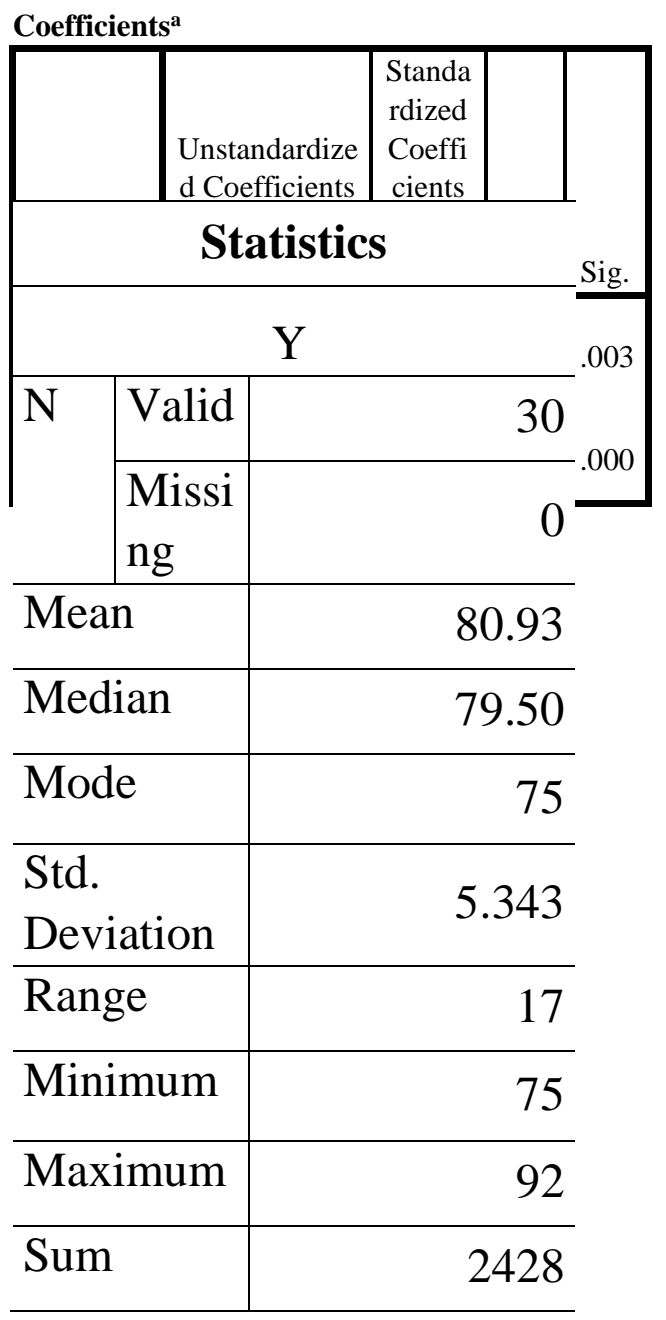

Adapun tabel distribusi frekuensi hasil belajar dapat dilihat dalam bentuk
Tabel distribusi frekuensi di atas dapat dilihat dalam bentuk grafik

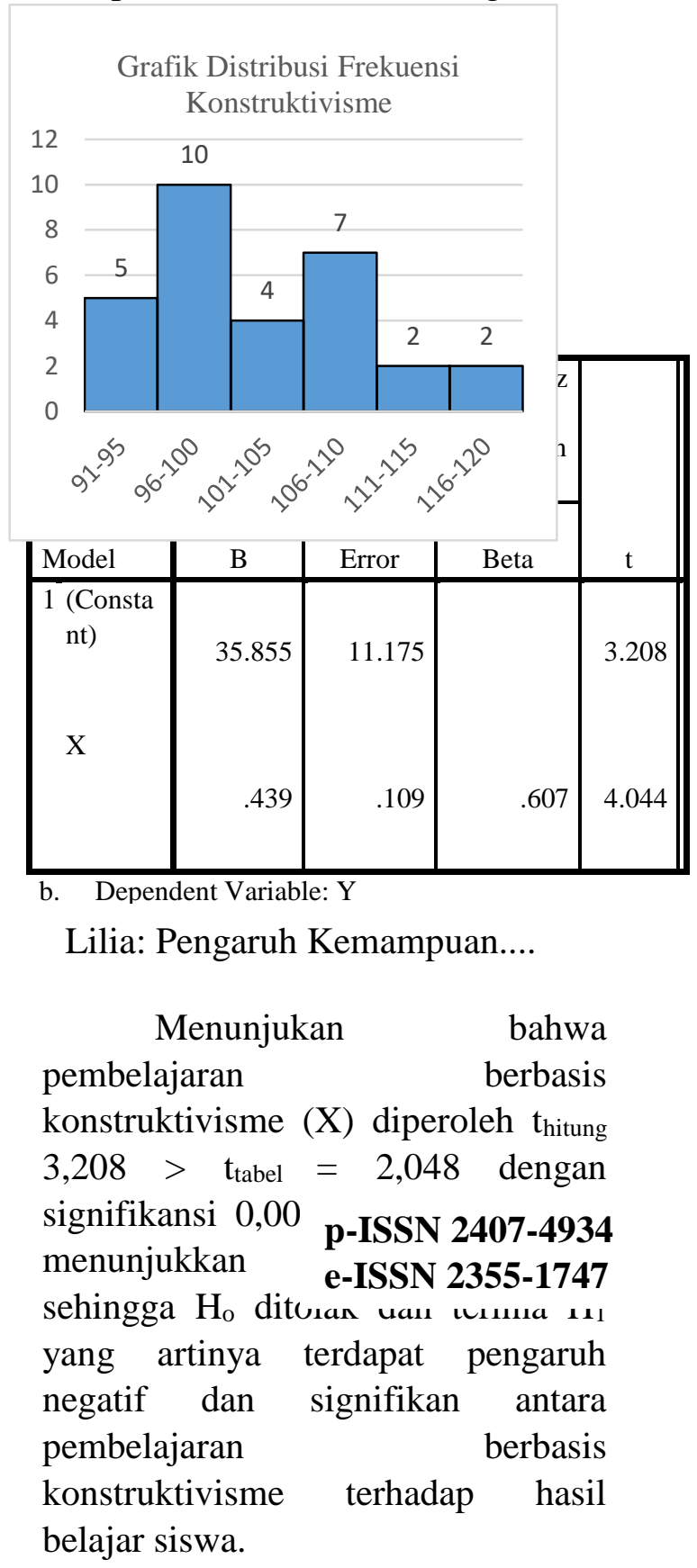

SIMPULAN 
Berdasarkan data yang telah dianalisis dari hasil penelitian tentang Pengaruh Kemampuan Pengelolaan Pembelajaran Berbasis Konstruktivisme terhadap Hasil Belajar Mata Pelajaran PKN di Kelas V A SDN Jelambar Baru 01 Pagi Jakarta Barat Tahun Pelajaran 2018/2019. Maka $\mathrm{H}_{\mathrm{o}}$ ditolak dan $\mathrm{H}_{1}$ diterima. Dengan demikian, dapat disimpulkan bahwa terdapat pengaruh yang signifikan antara pembelajaran berbasis konstruktivisme terhadap hasil belajar mata pelajaran PKN di kelas V A SDN Jelambar Baru 01 Pagi.

\section{DAFTAR PUSTAKA}

Aunurrahman. 2012. Belajar dan Pembelajaran. Bandung: Alfabeta

Budianti, I. S., Albert, L., \& Sulistiowati, D. (2013). Pengaruh Pendekatan Konstruktivisme Terhadap Hasil Belajar Siswa Kelas VIII SMPN 11 Jayapura Pada Pokok Bahasan Getaran dan Gelombang Tahun Ajaran 2012/2013 Indah. Jurnal Ilmu Pendidikan, 19(2), 218-224. Retrieved from \begin{tabular}{ll} 
p-ISSN 2407-4934 & l/index.ph \\
e-ISSN 2355-1747 & \multicolumn{1}{c}{$/ 1202$}
\end{tabular}

Hanafy, M. S. (2014). Konsep Belajar dan Pembelajaran. Jurnal Lentera Pendidikan, 17(1), 6679. Retrieved from doi: https://doi.org/10.24252/lp.2014 v17n1a5

Indrawati. (2017). Pengaruh Metode
Scaffolding Berbasis

Konstruktivisme Terhadap Hasil

Belajar Matematikaa. Journal of Medives, 1(1), 9-16.

Jauhari, H., Kusmayadi, T. A., \& Mardiyana. (2014). Pendekatan Pembelajaran Pendidikan Matematika Realistik Indonesia Dan Pendekatan Pembelajaran Konstruktivisme Menggunakan Teknik Hypnosis In Teaching Pada Materi Geometri Siswa Kelas VII Mts Di Kabupaten Ponorogo. Juurnal Elektronik Pembelajaran Matematika, 2(1), 15-28.

Manurung, A. S. (2017). Kontribusi Model Pembelajaran Pakem Terhadap Hasil Belajar Matematika Siswa Kelas XI IPA SMAN 31 Jakarta, 7.

Melinda, I., \& Susanto, R. (2018). Pengaruh Reward dan Punishment Terhadap Motivasi Belajar Siswa. Internasional Jurnal of Elementary Education, 2(2), 81-86.

ESJ VOLUME

Santi, J. (2015). Penerapan Pendekatan Konstruktivisme Untuk Meningkatkan Hasil Belajar Siswa Pada Pokok Bahasan Tumbuhan Hijau di Kelas V SDN 3 Tolitoli. Jurnal Kreatif Tadulako, 4(3), 57-71.

Siregar, Eveline dan Hartini Nara. (2010). Teori Belajar dan Pembelajaran. Jakarta: Gahlia Indonesia

Sugiyono. (2012). Metode Penelitian 
Kuantitatif,Kualitatif, dan $R \& D$. Bandung: Alfabeta

Susanto, Ahmad. (2018). Teori Belajar dan Pembelajaran di Sekolah Dasar. Jakarta: Kencana

Supardi. (2016). Aplikasi Statistika dalam Penelitian, Jakarta: PT Prima Ufuk Semesta

Supardan, D. (2016). Teori Dan Praktik Pendekatan Konstruktivisme Dalam Pembelajaran. Edunomic, 4(1), 1-12.

Susanto, R. (2017). Senam Otak Dan Pengaruhnya Terhadap Kesiapan Belajar Dan Hasil Belajar Mata Kuliah Metode Penelitian Mahasiswa PGSD, FKIP Universitas Esa Unggul, Jakarta . Prosiding Seminar Nasional Mullti Disiplin Ilmu \& Call For Papers Unisbank Ke-3, (1), 821-829. Retrieved from http://www.unisbank.ac.id/ojs/i ndex.php/sendi_u/issue/view/31 7 